\title{
AVALIAÇÃO DA ATIVIDADE CICATRIZANTE DO ÓLEO DE PEQUI (CARYOCAR CORIACEUM WITTM) EM FERIDAS CUTÂNEAS PRODUZIDAS EXPERIMENTALMENTE EM RATOS
}

\author{
J.S. Batista, A.E. Silva, C.M.F. Rodrigues, K.M.F.M. Costa, \\ A.F. Oliveira, E.S. Paiva, F.V.A. Nunes, R.G. Olinda
}

${ }^{1}$ Universidade Federal Rural do Semi-Árido, Departamento de Ciências Animais, Laboratório de Patologia Veterinária, CP 137, CEP 59625-900, Mossoró, RN, Brasil. E-mail: jaelsoares@hotmail

\author{
RESUMO
}

\begin{abstract}
O objetivo deste estudo foi demonstrar os efeitos do tratamento tópico do creme à base de óleo de pequi (Caryocar coriaceum Wittm) utilizando 40 ratos (Rattus norvegicus albinus) da linhagem Wistar, machos, com 60 dias de idade. Esses foram divididos em dois grupos: I) composto por 20 ratos com feridas cutâneas tratados com aplicação tópica do creme base com 10\% de óleo de pequi; II) com o mesmo número de animais que receberam a aplicação tópica do creme base sem o óleo de pequi. Após antissepsia e anestesia local foi produzida cirurgicamente ferida circular de $1 \mathrm{~cm}$ de diâmetro na região dorso lombar. As lesões cutâneas foram avaliadas sob o aspecto clínico, morfométrica e histológico no $3^{\circ}, 7^{\circ}, 14^{\circ}$ e $21^{\circ}$ dias pós-operatório. No grupo tratado com creme à base de óleo de pequi houve aceleração na evolução do processo cicatricial. As feridas dos animais desse grupo apresentaram redução significativa a partir do décimo quarto dia pós-operatório, bem como foram verificados nesse período achados histológicos característicos da etapa final do processo de cicatrização tais como: acentuada quantidade de fibroblastos, fibras colágenas e completo processo de reepitelização, enquanto que as feridas do grupo controle necessitaram de mais tempo para resolução do processo cicatricial.
\end{abstract}

PALAVRAS-CHAVE: Caryocar coriaceum, pequi, cicatrização de feridas, ratos.

\section{ABSTRACT}

EVALUATIONOF THEHEALING ACTIVITY OF PEQUI(CARYOCAR CORIACEUMWITTM) OIL IN CUTANEOUS WOUNDS INDUCED EXPERIMENTALLY IN RATS. The main objective of this study was to demonstrate the effects of topical treatment with ointment containing pequi oil (Caryocar coriaceum Wittm), using 40 male 60-day-old mice (Rattus norvegicus albinus) from the Wistar line. These were divided into two groups: I) composed by 20 mice with cutaneous wounds treated by topical application of the ointment based on $10 \%$ pequi oil; II) the same number of mice, receiving the topical application of ointment without pequi oil. After antisepsis and local anesthesia, round 1-cm-diameter wounds were made on the lower back region. The wounds were evaluated in regard to clinical, morphometric and histological aspects on the 3rd, 7th, 14th and 21st postoperative days. The group treated with the pequi ointment presented acceleration in the healing process. The animals' wounds of this group showed a meaningful reduction from the 14 th postoperative day, when histological characteristics from the ending of the healing process were noted, such as a large amount of fibroblasts, collagen fibers and a complete process of reepithelialization, while the wounds of the control group needed more time for the healing process.

KEY WORDS: Caryocar coriaceum, pequi, healing process, mice.

\section{INTRODUÇÃO}

O pequizeiro, conhecido pelos nomes vulgares de pequi, piqui, pequá, amêndoa do espinho, grão de cavalo ou amêndoa do Brasil é uma espécie arbórea nativa do Cerrado Brasileiro pertencente à família Caryocaraceae. Ocorre em quase todos os agroecossistemas do país e tem seus frutos muito apreciados e utilizados na culinária da região Centro-Oeste, Norte e parte do Nordeste. Na parte mais setentrional do Nordeste Brasileiro é encontrada a espécie Caryocar coriaceum, que exerce importante papel sócio-econômico naChapada do AraripeecircunvizinhançasnosEstados do Ceará, Pernambuco e Piauí (Oliverra et al., 2008).

Da polpa e da amêndoa do fruto é extraído um óleo que apresenta grande versatilidade quanto 
ao seu uso, com aplicações que vão da culinária regional até a indústria cosmética, para a produção de sabonetes e cremes (PiAnovski et al., 2008), além de apresentar potencial de uso para a produção de combustíveis elubrificantes (OliverRa et al., 2008). Na medicina popular, são atribuídas diversas propriedades medicinais à planta e seus frutos, as cascas da árvore e dos frutos são utilizadas em infusões como antifebris e diuréticos (CORREIA, 1926), as folhas no tratamento de resfriados, gripes, edemas e o óleo do fruto é usado para tratamento de queimadura, como afrodisíaco (VIEIRA; MARTINS, 2000), e como bálsamo em casos de reumatismo (BRANDÃo et al., 2002).

Ovalor terapêutico do pequizeiro atribuído à medicina popular vem sendo pesquisado e uma ampla variedade de experimentos científicos atesta sua real eficácia. Extrato da cera epicular extraído das folhas do pequizeiro demonstrou atividade antifúngica, por inibir o crescimento de Cryptococcus neoformans (PAssos et al., 2002), além de apresentar atividade mulicida por combater o hospedeiro intermediário causador da esquitossomose (RomAncini; Aquino, 2007), efeito leishmanicida por inibir a proliferação da forma promastigota da Leishmania amazonensis e atividade antimicrobiana por inibir o crescimento de enterobactérias (PAULA-JúNIOR et al., 2006). O extrato da casca do pequizeiro demonstrou interferência sobre a curva de parasitemia do Trypanosoma cruzi, reduzindo o número de parasitos no sangue(HERzOGSOARES et al., 2002). No óleo extraído da polpa foram encontrados antioxidantes naturais que diminuíram o estresse oxidativo e, consequentemente, promoveu proteção contra danos ao DNA (MiRANDA-VILELA et al., 2008).

Apesar de ser descrito o uso do pequizeiro no tratamento de uma ampla variedade de enfermidades, no que se refere sua utilização como cicatrizante não se observaram, na literatura pesquisada, estudos que avaliassem o efeito reepitelizante do óleo de pequi, o que motivou a escolha do óleo do Caryocar coriaceum Wittm como substância a ser avaliada na presente pesquisa.

\section{MATERIAL E MÉTODOS}

Os frutos do pequizeiro dos quais foram extraído o óleo utilizado no presente estudo foram coletados no chão, após queda natural, no Município de Dermerval Lobão, Piauí, em dezembro de 2008. A classificação taxonômica da árvore foi realizada através da identificação de suas folhas e flores no Herbarium Dárdano de Andrade Lima, da Universidade Federal Rural do Semi-árido - UFERSA, com registro $n^{\circ} 11.565$.

Para obtenção do óleo, o fruto do pequi foi despolpado manualmente e fatias da polpa foram submetidas à secagem em estufa digital com circulação forçada de ar a $60^{\circ} \mathrm{C}$, durante 48 horas e em seguida, triturado em moinho de bola. O óleo foi extraído após o cozimento intensivo do produto com água, seguido da separação do sobrenadante, secagem em recipiente metálico sobre uma chapa quente e separação dos resíduos em papel de filtro, tal como descrito por FACIOLI; GonçALVES (1998). Para a preparação da formulação tópica a ser aplicada nos animais, foi utilizado o creme base constituído de oleato de isodecila 5\%, lanete WB 10\%, butil-hidroxtolueno (BHT) 0,01\%, EDTA 0,1\%, aristoflex 1,5\%, propilenoglicol $5 \%$, silicone BC245 2\%, Phenonip ${ }^{\circledR}$ 0,1\% e água bidestilada q.s.p. 100 g. Foram adicionados $10 \%$ de óleo de pequi em $100 \mathrm{~g}$ do creme base.

Foram utilizados 40 ratos (Rattus norvegicus albinus) (Projeto aprovado UFERSA PI09I0A-52) da linhagem Wistar, machos, com 60 dias de idade, pesandoaproximadamente $120 \mathrm{~g}$, acondicionadosem gaiolas de plástico, em condições de temperatura e umidade ambientais. Os animais foram submetidos às condições de manejo idênticos, alimentados com ração comercial (Labina Purina $\left.{ }^{\circledR}\right)$ e água à vontade.

Para o delineamento experimental, os animais foram divididos, aleatoriamente, em dois grupos. O grupo I foi composto por 20 ratos com feridas cutâneas tratadas com aplicação tópica do creme base com $10 \%$ de óleo de pequi, e o grupo II, com o mesmo número de animais quereceberam a aplicação tópica do creme base sem o óleo de pequi, sendo este grupo considerado controle.

Para a realização das feridas cutâneas, os animais foram anestesiados com anestesia dissociativa utilizando cloridrato de xilazina $(8,0 \mathrm{mg} / \mathrm{kg})$ e cloridrato de quetamina $(140 \mathrm{mg} / \mathrm{kg})$, administrada por via intramuscular. Após anestesia, foram feitas tricotomia e antisepsia com álcool iodado $2 \%$ no local cirúrgico. Uma lesão circular de $1 \times 1 \mathrm{~cm}$ de diâmetro foi realizada na pele da região dorsolombar com auxílio de lâmina de bisturi, tesoura romba e pinça de dissecção. O creme foi aplicado imediatamente após cirurgia e, posteriormente, uma vez ao dia com auxílio de espátulas de madeiras estéreis e individuais.

Após a contenção dos animais em decúbito ventral sobre uma prancha de madeira, realizou-se a tricotomia da região dorsolombar e demarcação da área da ferida, com auxílio de um marcador vazado circular de $1 \times 1 \mathrm{~cm}$ de diâmetro. A área da pele demarcada foi então incidida com lâmina de bisturi n. 15 e divulsionada da tela subcutânea com tesoura romba e pinça de dissecção, ficando exposta a fáscia muscular. O creme foi aplicado imediatamente após cirurgia e, posteriormente, uma vez ao dia com auxílio de espátulas de madeiras estéreis e individuais.

Em todos os animais as lesões cutâneas foram observadas diariamente quanto à presença de 
hiperemia, edema, sangramento, secreção, odor e crostas. As áreas das feridas foram medidas nos diâmetros maior e menor empregando-se paquímetro no dia 0 (dia de produção das lesões cutâneas) e nos dias $3^{\circ}, 7^{\circ}, 14^{\circ}$ e $21^{\circ}$ pós-operatório.

Concomitante à mensuração da área da lesão, os ratos foram sacrificados com dose inalatória letal de éter etílico. Incisões abrangendo a área da lesão e pele íntegra foram realizadas em cada animal. Os fragmentos foram fixados em formalina a $10 \%$ e submetidos à inclusão em parafina, para obtenção de cortes de $5 \mu \mathrm{m}$ de espessura e corados pelo método de hematoxilina-eosina (LunA, 1968).

Para verificar microscopicamente a evolução da cicatrização foram considerados os seguintes achados histológicos: células polimorfonucleares, células mononucleares, proliferação vascular, proliferação fibroblástica, reepitelização e colagenização. A intensidade dos achados histológicos foi transformada em variáveis quantitativas mediante a atribuição de índices: ausente (0), discreto (1), moderado (2) e acentuado (3) (GARROS et al., 2006).

Para a obtenção da área das feridas utilizou-se a equação formulada por PRATA et al. (1988): A = $\Pi$. R. $r$, onde A representa a área $\left(\mathrm{cm}^{2}\right)$; “ $R$ ", o raio maior

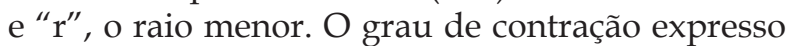
em percentual foi mensurado pela equação proposta por RAMSEY et al. (1995), onde Wo = área inicial da ferida e Wi = área da ferida no dia da biópsia:100 x $(\mathrm{Wo}-\mathrm{Wi}) / \mathrm{Wo}=\%$ de contração.

Os resultados de área e contração das feridas foram expressos em média \pm desvio padrão, submetidos à análise de variância e ao teste de Tukey, considerando-se significativo os valores comparados ao nível de 5\% de significância.

\section{RESULTADOS E DISCUSSÃO}

Ao exame macroscópico, no terceiro dia pósoperatório as feridas dos animais pertencentes ao grupo tratado com óleo de pequi e controle apresentaram-se hiperêmicas e com bordos edemaciados. No sétimo dia pós-operatório as feridas tratadas com óleo de pequi apresentaram-se recobertas por uma crosta fina, nivelada com a pele e sem evidências de inflamação, porém, estas alterações não foram observadas no mesmo período no grupo controle, cujas feridas permaneceram hiperêmicas, com bordos edemaciados e exudato purulento em três animais.

Observou-se que as feridas dos animais do grupo controle permaneceram maiores que as do grupo tratado com óleo de pequi. Ocorreu diminuição da área das feridas ao longo do tempoe no décimo quarto dia pós-operatório a área encontrada apresentava médias de $0,376 \mathrm{~cm}^{2} \mathrm{e} 0,031 \mathrm{~cm}^{2}$, para os grupos con- trole e tratado com óleo de pequi, respectivamente, sendo a diferença entre as médias estatisticamente significativa $(p=0,05)$ (Fig. 1). No referido período, o grupo controle apresentou percentual de contração de $52,0 \%$, enquanto o grupo tratado com óleo de pequi foi de $96,0 \%$ (Fig. 2). As mensurações foram realizadas até o décimo quarto dia pós-operatório, pois, após este dia, as feridas encontravam-se cicatrizadas, com fechamento total dos bordos, enquanto que as feridas dos animais do grupo controle ainda necessitavam de mais tempo para a resolução do processo cicatricial.

$\mathrm{Na}$ avaliação histológica verificou-se, no terceiro dia em todos os animais dos grupos controle e tratados com óleo de pequi, a presença de crosta fibrino-leucocitária espessa, acentuado infiltrado de células polimorfonucleares, fibrina e detritos celulares. Avaliando-se as feridas ao sétimo dia foi possível observar, no grupo controle, que achados histológicos foram semelhantes aos observados no terceiro dia (Fig. 3). Constatou-se no sétimo dia do grupo tratado comóleo de pequi a presença de crosta fina, moderada quantidade de células mononucleadas (monócitos e macrófagos), além de acentuado quantidade de vasos neoformados, fibroblasto e hiperplasia do epitélio (Fig. 4). A análise histológica também demonstrou que no décimo quarto dia as feridas dos animais do grupo controle apresentavam crostas, moderada quantidade de células polimorfonucleares, além de discreta quantidade de vasos neoformados e fibroblastos (Fig. 5). No mesmo período, as feridas dos animais do grupo tratado com óleo de pequi apresentavam-se reparadas em relação ao grupo controle, visto que se verificou nesse período achados histológicos característicos da etapa final do processo de cicatrização, tais como acentuada quantidade de fibroblastos, fibras colágenas e completo processo de reepitelização (Fig. 6).

Nesse estudo utilizou-se técnica asséptica para manter as feridas sem qualquer contaminação, no entanto, verificou-se secreção purulenta em três animais do grupo controle, que era ausente nos animais do grupo tratado com óleo de pequi. Esse fato pode ser atribuído a uma possível atividade antimicrobiana do óleo da polpa do Caryocar coriaceum Wittm. PAula-Junior et al. (2006) demonstraram o efeito antibacteriano do Caryocar brasiliense Cambess contra Enterococcus faecalis, Escherichia coli, Pseudomonas aeruginosa e Staphylococcus aureus, concluindo que substâncias antioxidantes presentes no extrato hidroetanólico das folhas do pequizeiro são responsáveis pela atividade antimicrobiana desse fitoterápico.

Outro dado importante refere-se à intensidade da inflamação discreta presentenos exames macroscópicos e histológicos das feridas nos animais do grupo tratado com óleo de pequi, também observada por SARAIVA et al. (2008). 
O processo inflamatório promove a exsudação de células leucocitárias que fagocitam e destroem agentes lesivos, restos tissulares e tecido necrótico, sendo portando a inflamação necessária para a boa resposta da reparação tecidual (MANDELBAUM et al., 2003). Entretanto, reação inflamatória intensa pode prejudicar o processo de reparo por promover edema, quantidade excessiva de exsudato, os quais favorecem deiscência, crescimento bacteriano e, consequentemente, a inibição da proliferação de fibroblastos e da deposição de colágeno (COTRAN et al., 2009).

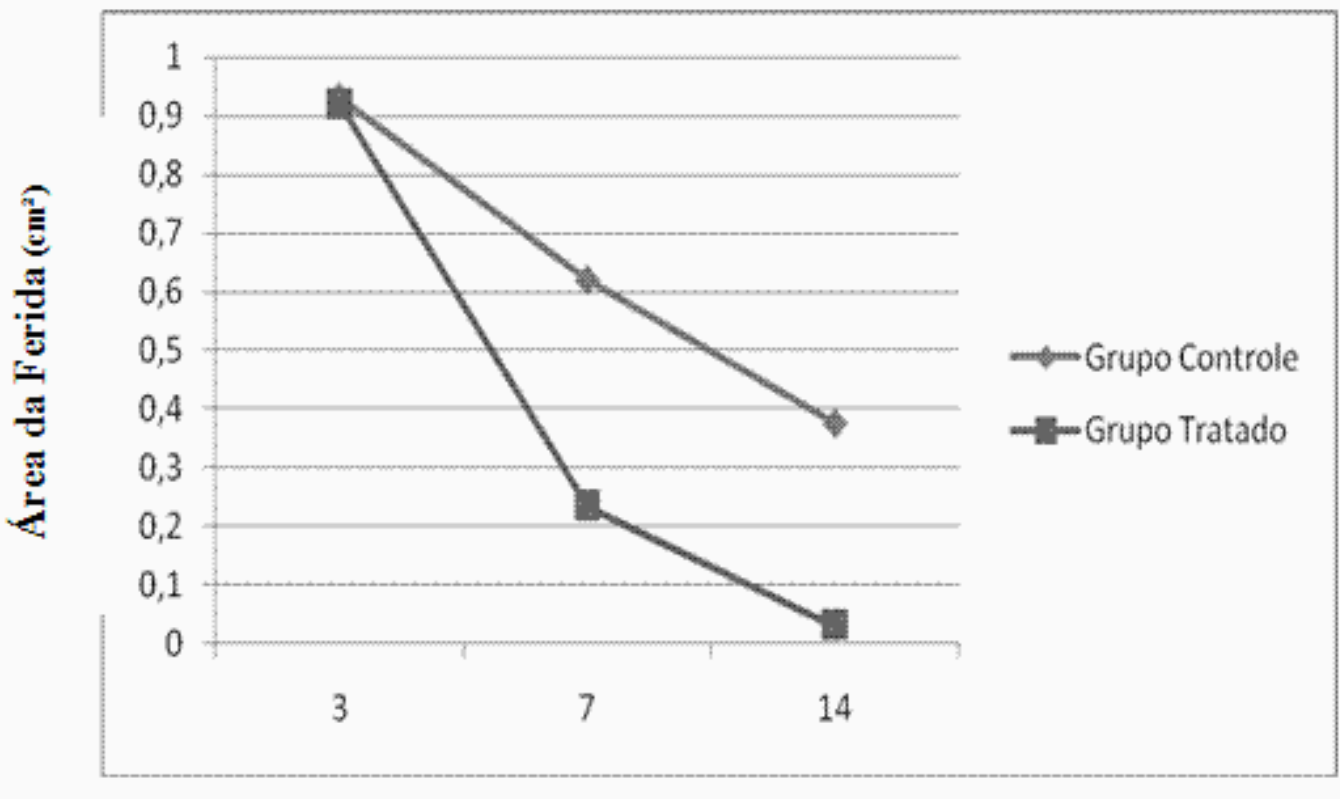

Dias

Fig. 1 - Valor médio $\left(\mathrm{cm}^{2}\right)$ da área das feridas ao 3ํ dia, 7o dia e 14ํ dia de evolução pós-cirúrgica das feridas cutâneas dos grupos controle e tratado com óleo de pequi.

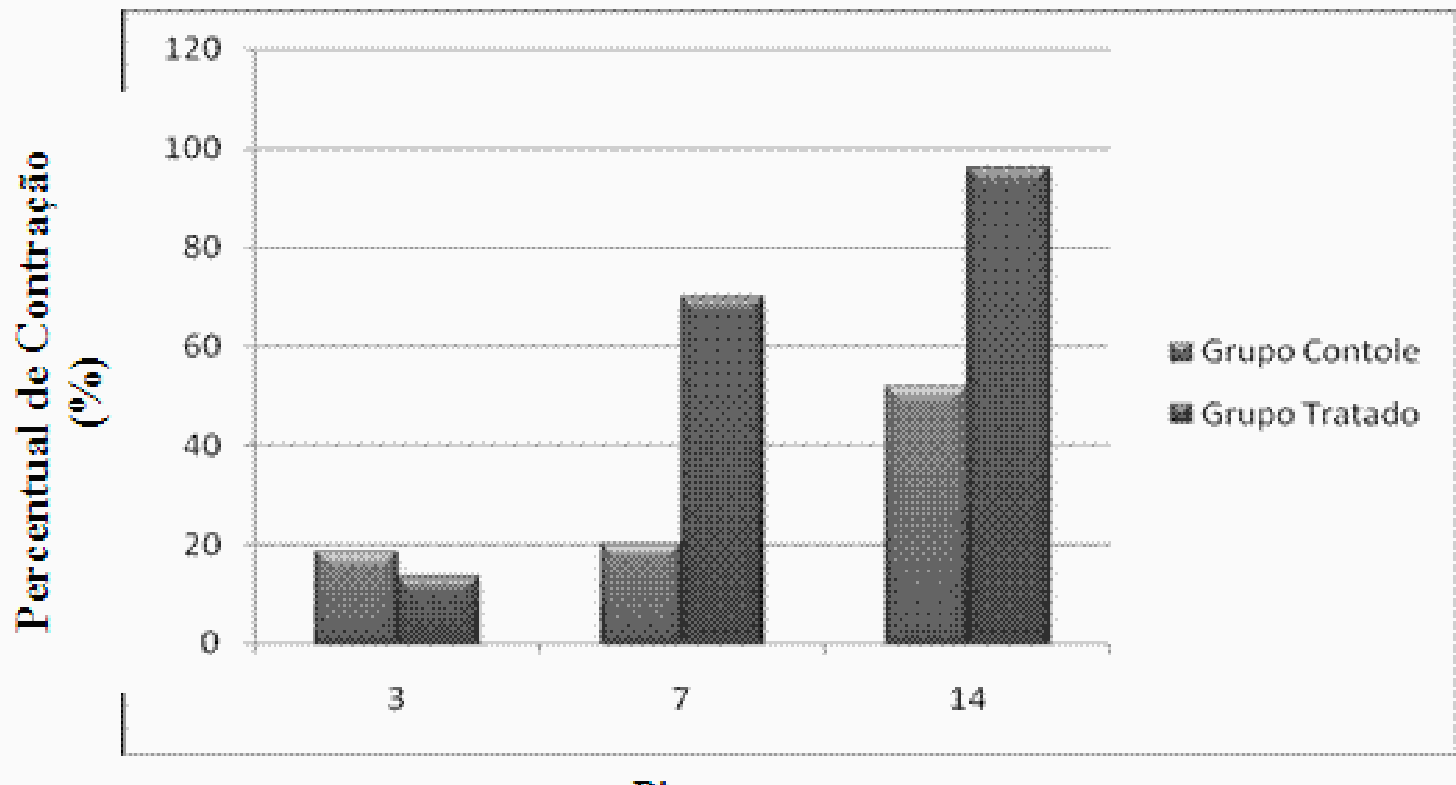

\section{Dias}

Fig. 2 - Valor médio do percentual de contração ao 3o dia, 7ํ dia e 14ํㅜㄹia de evolução pós-cirúrgica das feridas cutâneas dos grupos controle e tratado com óleo de pequi. 


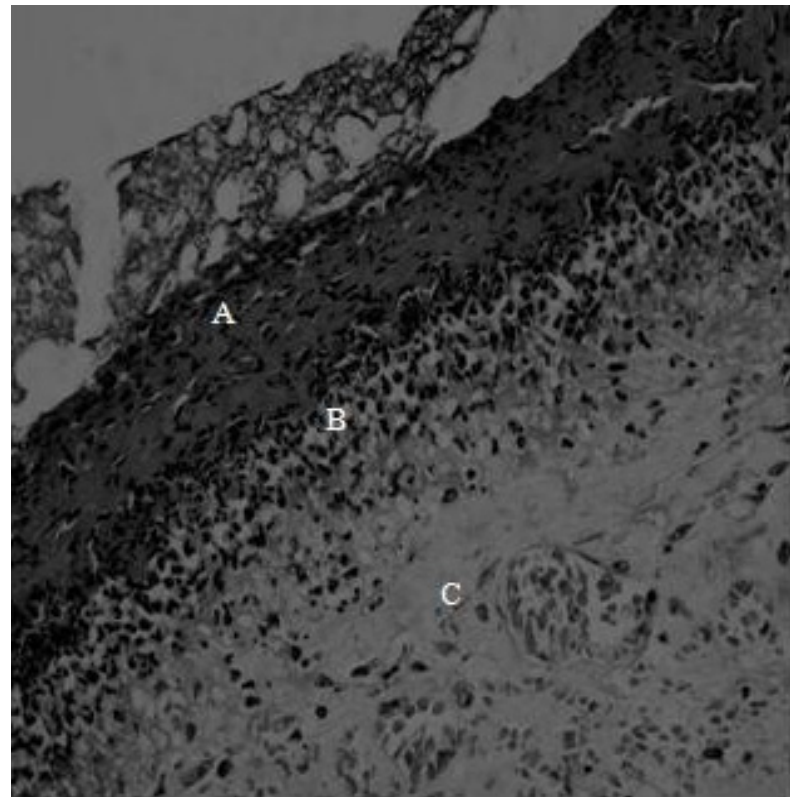

Fig. 3 - Aspecto histológico das feridas cutâneas ao $7^{\circ}$ dia deevolução pós-cirúrgica do grupo controle. Hematoxilina e Eosina. Aumento 400x. A - crosta; B - infiltrado inflamatório e C - tecido de granulação.

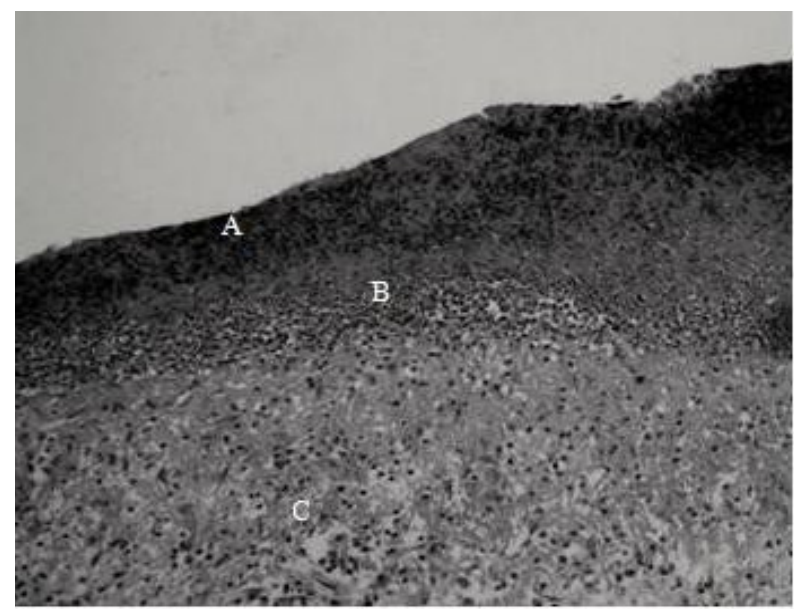

Fig. 5 - Aspecto histológico das feridas cutâneas ao $14^{\circ}$ dia deevolução pós-cirúrgica do grupo controle. Hematoxilina e Eosina. Aumento 400x. A - crosta; B - infiltrado inflamatório e C - tecido de granulação.

Noóleo da polpa e semente de espécies do gênero Caryocar estão presentes substâncias descritas na lite-ratura como capazes de promover efeito benéfico no tratamento de feridas cutâneas. O óleo da polpa do Caryocar brasiliense Camb apresenta quantidades expressivas de beta $\beta$-coroteno, licopeno, carotenoides totais (BRANDÃo et al., 2002; OliveIRA et al., 2006) e compostos fenólicos (Limaetal.2007; MiRANDA-VILELA et al., 2008). Carotenoides presentes no C. brasiliense exibem ação antioxidante que impedem a lipoperoxidação e conferem proteção à pele (PIANOVSKI et al., 2008). Compostos fenólicos representam um dos principais grupos de substâncias com atividades

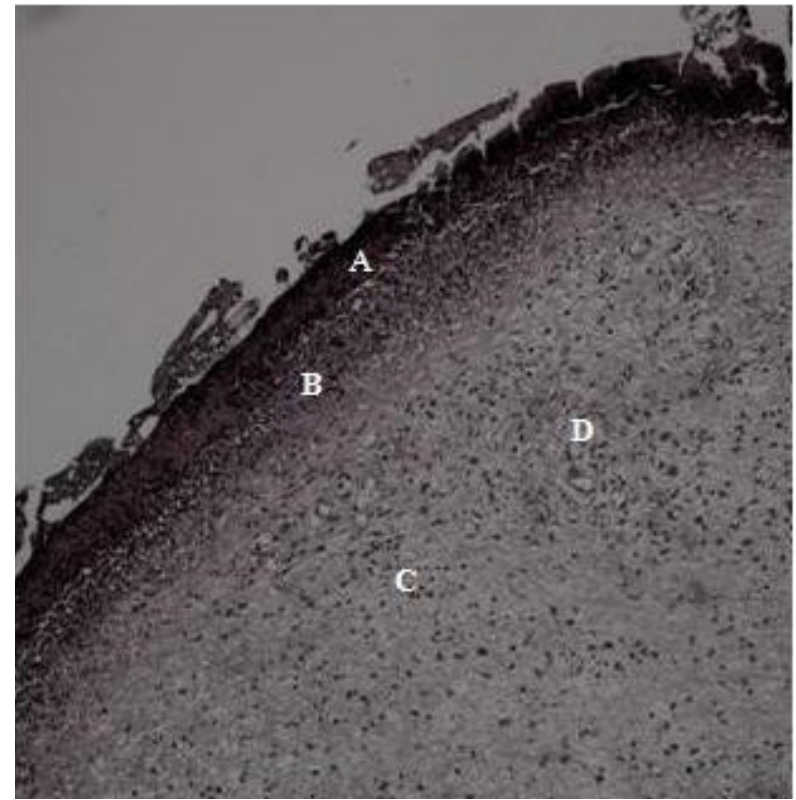

Fig. 4 - Aspecto histológico das feridas cutâneas ao $7^{\circ}$ dia de evolução pós-cirúrgica do grupo tratado com óleo de pequi. Hematoxilina e Eosina. Aumento 400x. A - crosta; B - infiltrado inflamatório, C - tecido de granulação e D - vasos neoformados.

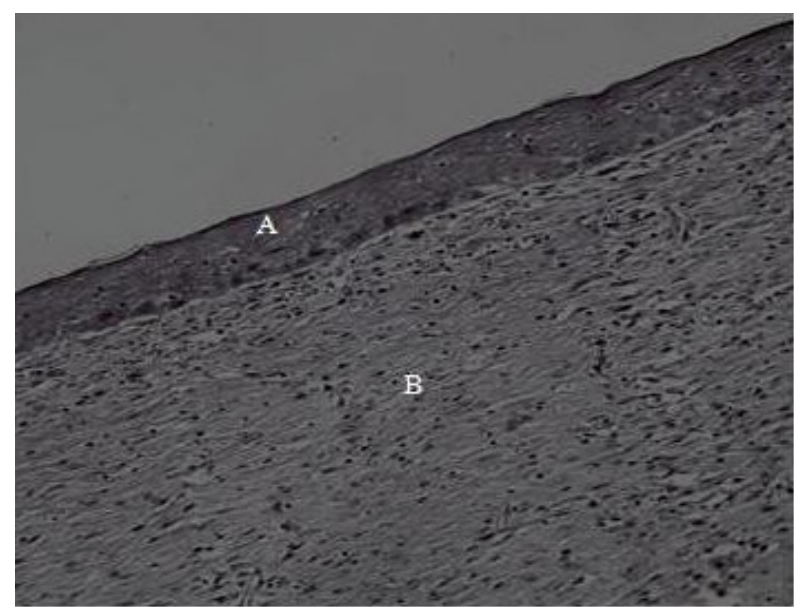

Fig. 6 - Aspecto histológico das feridas cutâneas ao $14^{\circ}$ dia de evolução pós-cirúrgica do grupo tratado com óleo de pequi. Hematoxilina e Eosina. Aumento 400x. A - epitélio; B - tecido de granulação.

farmacológicas em plantas, são utilizados para elevar a eficácia do processo de cicatrização em feridas e úlceras; agindo como antioxidantes, combatem os radicais livres, possuem atividade antimicrobiana e moduladora do sistema imune e apresentam ação anti-inflamatória (VIEIRA et al., 2008).

Dados da composição química do Caryocar brasiliense Camb. mostram alto teor de lipídios tanto na polpa quanto na amêndoa, destacando-se neles a presença dos ácidos graxos insaturados, predominando o ácido oléico como principal componente entre os ácidos graxos (FACIOLI; GonçALVES, 1998; LiMA et al., 2007). O óleo da polpa de Caryocar coriaceum 
Wittm. possui ácido oléico (56,34\%), ácido palmítico (27,63\%), ácido linoleico (5,2\%) e linolênico (4,42\%) (Lima et al., 1981).

A alta concentração de ácidos graxos insaturados no óleo de pequi sugere boa perspectiva na utilização desse produto como alternativa terapêutica para a cicatrização. Os ácidos graxos insaturados promovem a obtenção decurativo úmido oleoso, que serve como barreira protetora contra micro-organismos, evitam a desidratação tecidual, mantém a temperatura corpórea e diminui os traumatismos, atuam como um poderoso mediador pró-inflamatório, estimulam a produção fatores de crescimento, promovem a fibroplasia, e a neovascularização e são bactericidas (MANDelbaum et al., 2003; Marques et al., 2004; HATANAKA; CURI, 2007).

\section{CONCLUSÃO}

A análise do processo de cicatrização sob os pontos de vista clínico, macroscópico e histológico permitiu concluir que o uso do óleo da polpa do fruto do Caryocar coriaceum Wittm apresentou influência positiva na cicatrização de feridas cutâneas experimentais em ratos, por promover reação inflamatória menos intensa e fechamento mais rápido das feridas em relação ao grupo controle.

\section{REFERÊNCIAS}

BRANDÃO, M.; LACA-BUENDÍA, J.P.; MACEDO, J.F. Árvores nativas e exóticas do Estado de Minas Gerais. Belo Horizonte: EPAMIG, 2002. 528p.

COTRAN, R.S.; KUMAR, V.; COLLINS, T. Robbins patologia funcional e estrutural. 6.ed. Rio de Janeiro: Guanabara Koogan, 2009. 1252p.

CORRÊA, M.P. Dicionário das plantas úteis do Brasil e exóticas cultivadas. Rio de Janeiro: Ministério da Agricultura, 1926. v.1., 747p.

FACIOLI, N.L.; GONÇALVES, L.A.G. Modificações por via enzimática da composição triglicerídica do óleo de pequi (Caryocar brasiliensis Camb.) Química Nova, v.21, n.1, p.16-19. 1998.

GARROS, I.C.; CAMPOS, A.C.L.; TIMBARA, E.M.; TENÓRIO, S.B.; TORRES, O.J.M.; AGULHAM, M.A.; ARAÚJOA, C.F.; SANTIS-ISOLAN, P.M.B.; OLIVEIRA, R.M.; ARRUDA, E.C.M. Extrato de Passiflora edulis na cicatrização de feridas cutâneas abertas em ratos: estudo morfológico e histológico. Acta cirúrgica Brasileira, v.2, p.55-65, 2006.

HATANAKA, E.; CURI, R. Fatty acids and wound healing: a review. Revista Brasileira de Farmácia, v.88, n.2, p.53-58, 2007.
HERZOG-SOARES, J. D.; ALVES, R. K.; ISAC, E.; BEZERRA, J. C. B.; GOMES, M. H.; SANTOS, S. C.; FERRI, P. H. Atividade tripanocida in vivo de Stryphnodendron adstringens (barbatimão verdadeiro) e Caryocar brasiliensis (pequi). Revista Brasileira de Farmacognosia, v.12, p.1-2, 2002. Suplemento.

LIMA, A.; SILVA, A.M.O.; TRINDADE, R.A. TORRES, R.P.; MANCINI FILHO, J. Composição química e compostos bioativos presentes na polpa e na amêndoa do pequi (Caryocar brasiliense, Camb.). Revista Brasileira de Fruticultura, v.29, n.3, p.695-698, 2007.

LIMA, M.T.; MAIA, G.A.; GUEDES, Z.B.L.; ORIÁ, H.F. Composição de cidos graxos da fração lipídica do piqui (Caryocar coriaceum Wittm). Ciência Agronômica, v.12, n.1/2, p.93-96, 1981.

LUNA, L.G. Routine staining procedures. In: LUNA, L. G. Manual of histologic staining methods of the Armed Forces Institute of Pathology. 3.ed. New York: Mac Graw Hill, 1968. p.36-46.

MANDELBAUM, S.H.; DI SANTIS, E.P.; MANDELBAUM, M.H.S.A. Cicatrisation: current and auxiliary resources-Part 1. Anais Brasileiros de Dermatologia, v.78, n.4, p.393-410, 2003.

MARQUES, S.R.; PEIXOTO, C.A.; MESSIAS, J.B.; ALBUQUERQUE, A.R.; SILVA JÚNIOR, V.A. The effects of topical application of sunflower-seed oil on open wound in lambs. Acta Cirúrgica Brasileira, v.19, n.3, p.91103, 2004.

MIRANDA-VILELA, A.L.; RESCK, I.S.; GRISOLIA, C.K. Antigenotoxic activity and antioxidant properties of organic and aqueous extracts of pequi fruit (Caryocar brasiliense Camb.) pulp. Genetics and Molecular Biology, v.31, p.956-963, 2008.

OLIVEIRA, M.N.S.; GUSMÂO, E.; LOPES, P.S.N.; SIMÔES, M.O.M.; RIBEIRO, L.M.; DIAS, B.A.S. Estádio de maturação dos frutos e fatores relacionados o aspectos nutritivos e de textura da polpa de pequi (Caryocar brasiliense Camb.). Revista Brasileira de Fruticultura, v.28, n.3, p.380-386, 2006.

OLIVEIRA, M.E.B; GUERRA, N.B.; BARROS, L.M; ALVES, R.E. Aspectos agronômicos e de qualidade do pequi. Fortaleza: Embrapa Agroindústria Tropical, 2008. 32p. (Documentos, n.113)

PASSOS, X.S.; SANTOS, S.C.; FERRI, P.H.; FERNANDES, O.F.L.; FREITAS PAULA, T.; GARCIA, A.C.F.; SILVA, M.R.R. Atividade antifúngica de Caryocar brasiliensis (Caryocaraceae) sobre Cryptococcus neoformans. Revista da Sociedade Brasileira de Medicina Tropical, v.35, n.6, p.623-627, 2002.

PAULA-JUNIOR, W.; ROCHA, F.H.; DONATTI, L.; FADEL-PICHETH, C.M.T.; WEFFORT-SANTOS, A.M. Leishmanicidal, antibacterial, and antioxidant activities 
of Caryocar brasiliense Cambess leave hydroethanolic extract. Brazilian Journal of Pharmacognosy, v.16, p.625630, 2006.

PIANOVSKI, A.R.; VILELA, A.F.G.; SILVA, A.A.S.; LIMA, C.G.; SILVA, K.K.; CARVALHO, V.F.M.; MUSIS, C.R.; MACHADO, S.R.P.; FERRARI, M. Uso do óleo de pequi (Caryocar brasiliensis) em emulsões cosméticas: desenvolvimento e avaliação da estabilidade física. Revista Brasileira de Ciências Farmacêuticas, v.44, n.2, p.249-259, 2008.

PRATA, M.B.; HADDAD, C.M.; GOLDENBERG, S.; SIMÖES, M.J.; MOURA, L.A.R.; TRABULSI, L.R..Uso tópico do açúcar em ferida cutânea. Estudo experimental em ratos. Acta Cirúrgica Brasileira, v.3, n.2, p.43-48, 1988.

RAMSEY, D.T.; POPE, E.R.; WAGNER-MANN, C.; BERG, J.N.; SWAIN, S.F. Effects of three occlusive dressing materials on healing of full thickness skin wounds in dogs. American Journal of Veterinary Research, v.56, n.7, p.941-949, 1995.

ROMANCINI, R.M.; AQUINO, F.G. Aspectos da biologia reprodutiva do pequizeiro-anão (Caryocar brasiliense ssp. intermedium Camb., Caryocaraceae) em plantio experimental. In: ENCONTRO DE JOVENS TALENTOS
DA EMBRAPA CERRADOS, 3., 2007, Planaltina, DF. Resumo. Planaltina, DF: Embrapa Cerrados, 2007. p.49.

SARAIVA, R.A.; LEITE, G.O.; OLIVEIRA, R.C.; ARARUNA, M.K.A.; MENEZES, K.D.P.; PEREIRA, C.K.B.; COSTA, J.G.M.; CAMPOS, A.R.; MENEZES, I.R.A. Topical anti-inflammatory activity of Caryocar coriaceum Wittm. (Caryocaraceae) pulp fruit and seed oils. In: BRAZILIAN SYMPOSIUM ON MEDICINAL CHEMISTRY (SYSTEMS CHEMICAL BIOLOGY), 4., 2008, Porto de Galinhas. Anais. Porto de Galinhas, PE: Brazilian Chemical Society (SBQ), 2008.

VIEIRA, R.F.; MARTINS, M.V.M. Recursos genéticos de plantas medicinais do cerrado. Uma compilação de dados. Revista Brasileira de Plantas Medicinais, v.3, n.1, p.13-36, 2000.

VIEIRA, A.P.; SANTOS, N.R.; BORGES, J.H.S.; VINCENZI, M.P.A.; SCHMITZ, W.O. Ação dos flavonóides na cicatrização por segunda intenção em feridas limpas induzidas cirurgicamente em ratos Wistar. Semina. Ciências Biológicas e da Saúde, v.29, n.1, p.65-74, 2008.

Recebido em 30/11/09

Aceito em 29/7/10 